\title{
EFEKTIVITAS VERMIKOMPOS EISENIA FOETIDA SAVIGNY DALAM MEMPERBAIKI TINGKAT PRODUKSI DAN KUALITAS NUTRISI Sorghum bicolor (L.) Moench DAN Centrosema pubescens Benth
}

\author{
Asep Tata Permana ${ }^{1}$, Luki Abdullah², Panca Dewi Manuhara Karti ${ }^{3}$, \\ Toto Toharmat ${ }^{4}$, Suwarno ${ }^{5}$ \\ ${ }^{1}$ Mahasiswa Pasca Sarjana Ilmu Nutrisi dan Pakan, Fakultas Peternakan, IPB \\ 2,3, 4 Departemen IImu Nutrisi dan Teknologi Pakan, Fakultas Peternakan IPB \\ ${ }^{5}$ Departemen IImu Tanah dan Sumberdaya Lahan, Fakultas Pertanian, IPB \\ Corresponding email: aseptp@gmail.com
}

\begin{abstract}
ABSTRAK
Vermikompos merupakan salah satu produk organik hasil metabolisme cacing tanah. Eisenia foetida Savigny merupakan jenis cacing yang potensial menghasilkan vermikompos. Tujuan dari penelitian ini adalah untuk mengukur efektivitas vermikompos Eisenia foetida Savigny dalam memperbaiki tingkat produksi dan kualitas nutrisi Sorghum bicolor (L.) Moench dan Centrosema pubescens Benth pada level yang berbeda. Desain penelitian menggunakan rancangan acak lengkap (RAL) dengan 3 kali ulangan pada masing-masing tanaman. Level pemberian vermikompos yang diberikan adalah o\%, 25\%, 50\%, 75\%, dan 100\%. Jenis tanaman yang digunakan adalah Sorghum bicolor (L.) Moench dan Centrosema pubescens Benth. Hasil penelitian menunjukkan bahwa vermikompos efektif dalam meningkatkan produktivitas dan serapan nitrogen, fosfor dan kalium dari Sorghum bicolor (L.) Moench dan Centrosema pubescens Benth.
\end{abstract}

Kata kunci : vermikompos, produksi, kualitas nutrisi

\begin{abstract}
Vermicomspost is an organic product resulted from metabolism process of soil worm like Eisenia foetida Savigny. The experiment was conducted to evaluate the effectivity of vermicompost derived from E. Foetida Savigny in improvement of growth, biomass production and quality of Sorghum bicolor (L.) Moench and Centrosema pubescencs. The results showed that application of vermicompost effectively improved growth, biomass production and N, P, K content of above ground biomass of those experimental plants.
\end{abstract}

Keywords : vermicompost, productivity, quality.

\section{PENDAHULUAN}

Tanaman pakan yang berkualitas tinggi merupakan kebutuhan utama bagi ternak ruminansia. Untuk memperoleh tanaman yang seperti ini dibutuhkan tempat tumbuh yang subur yang dapat menunjang pertumbuhan tanaman supaya dapat tumbuh dengan baik. Hanya saja umumnya tanah yang ditanami oleh tanaman pakan merupakan tanah-tanah yang kurang subur, yaitu di antaranya mempunyai kandungan bahan organik dan unsur hara yang rendah. Dalam upaya perbaikan tanah seperti ini dibutuhkan penambahan unsur hara baik melalui pemupukan sintetis (pupuk anorganik) atau pupuk alami (pupuk organik). Pemakaian pupuk anorganik yang berlebihan dapat menyebabkan kerusakan tanah serta merupakan salah satu penyebab terjadinya pencemaran lingkungan. Sehingga pemakaian pupuk organik dapat merupakan alternatif untuk peningkatan kesuburan tanah.

Salah satu jenis pupuk organik yang dapat digunakan adalah vermikompos, yaitu pupuk hasil metabolisme cacing tanah. Pemberian vermikompos banyak digunakan untuk tanaman hortikultura tetapi masih kurang pemanfaatannya untuk tanaman pakan. Vermikompos digunakan sebagai pupuk organik karena mempunyai kandungan N, P, K yang cukup tinggi (Wani et al., 2012).

Penelitian ini bertujuan untuk melihat efektivitas penggunanaan vermikompos dalam peningkatan produksi dan kualitas nutrisi tanaman pakan Sorghum bicolor dan Centrosema pubescens.

\section{MATERI DAN METODE}

Penelitian ini dilakukan di rumah kaca Fakultas Peternakan IPB mulai bulan Mei hingga Juli 2013, menggunakan pot berukuran $5 \mathrm{~kg}$. Tanah latosol Darmaga (lolos ayakan $5 \mathrm{~mm}$ ) dan atau vermikompos (lolos ayakan $2 \mathrm{~mm}$ ) sesuai dengan perlakuan dimasukan ke dalam pot. Kedua bahan tersebut sebelum diayak dikeringudarakan dahulu. Beberapa sifat kimia tanah latosol Darmaga dan vermikompos disajikan dalam Tabel 1 dan Tabel 2. 
Tabel 1. Hasil Analisa Tanah Latosol Darmaga

\begin{tabular}{cccc}
\hline & Satuan & Nilai & Metoda \\
\hline $\mathrm{pH} \mathrm{H}_{2} \mathrm{O}$ & & 5.08 & $\mathrm{pH}$ meter \\
$\mathrm{pH} \mathrm{KCl}$ & & 4.31 & $\mathrm{pH}$ meter \\
$\mathrm{C}$ organik & $\%$ & 1.58 & Walkey \& Black \\
$\mathrm{N}$ total & $\%$ & 0.14 & Kjedahl \\
$\mathrm{P}$ tersedia & $\mathrm{ppm}$ & 0.78 & Bray I \\
$\mathrm{Ca} \mathrm{dd}$ & $\mathrm{cmol}(+) / \mathrm{kg}$ & 5.08 & Amonium asetat $1 \mathrm{M}(\mathrm{pH} \mathrm{7})$ \\
$\mathrm{Mg} \mathrm{dd}$ & $\mathrm{cmol}(+) / \mathrm{kg}$ & 1.34 & Amonium asetat $1 \mathrm{M}(\mathrm{pH} \mathrm{7})$ \\
$\mathrm{K} \mathrm{dd}$ & $\mathrm{cmol}(+) / \mathrm{kg}$ & 0.27 & Amonium asetat $1 \mathrm{M}(\mathrm{pH} 7)$ \\
$\mathrm{Al} \mathrm{dd}$ & $\mathrm{cmol}(+) / \mathrm{kg}$ & 0.99 & Volumetri \\
$\mathrm{H} \mathrm{dd}$ & $\mathrm{cmol}(+) / \mathrm{kg}$ & 0.11 & Volumetri \\
$\mathrm{KTK}$ & $\mathrm{cmol}(+) / \mathrm{kg}$ & 14.15 & Destilasi langsung \\
\hline
\end{tabular}

Vermikompos dan tanah yang telah diayak dimasukan ke dalam pot sesuai perlakuan yang diberikan, yaitu: VCo (o $\mathrm{kg}$ vermikompos, $4 \mathrm{~kg}$ tanah), VC25 (1 kg vermikompos, $3 \mathrm{~kg}$ tanah), VC5o (2 $\mathrm{kg}$ vermikompos, $2 \mathrm{~kg}$ tanah), $\mathrm{VC} 75$ (3 $\mathrm{kg}$ vermikompos, $1 \mathrm{~kg}$ tanah), VC10o (4 $\mathrm{kg}$ vermikompos, o $\mathrm{kg}$ tanah). Setiap perlakuan diulang dengan 3 ulangan menggunakan rancangan acak lengkap.

Sebelum ditanami benih sorgum dan centro, ke dalam pot ditambahkan bahan kapur sebanyak 12 g/pot dan pupuk NPK 15-15-15 sebanyak 2 g/pot. Masing-masing pot ditanami 10 benih dari masingmasing tanaman, setelah tumbuh dijarangkan menjadi 2 tanaman setiap potnya. Tanaman dipanen pada saat 7 minggu setelah tanam untuk diukur berat kering tanaman dan dianalisa kandungan $\mathrm{N}, \mathrm{P}$, dan $\mathrm{K}$ bagian atas tanaman (shoot).

\section{HASIL DAN PEMBAHASAN}

\section{Tinggi Tanaman dan Jumlah Daun}

Pertumbuhan tinggi tanaman dan jumlah daun berlangsung selama fase vegetatif. Pada masa vegetatif ini pemberian vermikompos meningkatkan tinggi tanaman dari masa awal tanam hingga akhir penelitian (Gambar 1). Penambahan vermikompos dari 25\% (VC25) hingga 100\% (VC10o) tidak terlalu terlihat perbedaannya dibandingkan dengan pengaruhnya pada centro. Walaupun demikian pemberian vermikompos 25\% (VC25) mempunyai kecenderungan tinggi tanaman yang lebih tinggi dibandingkan dengan perlakuan lain.
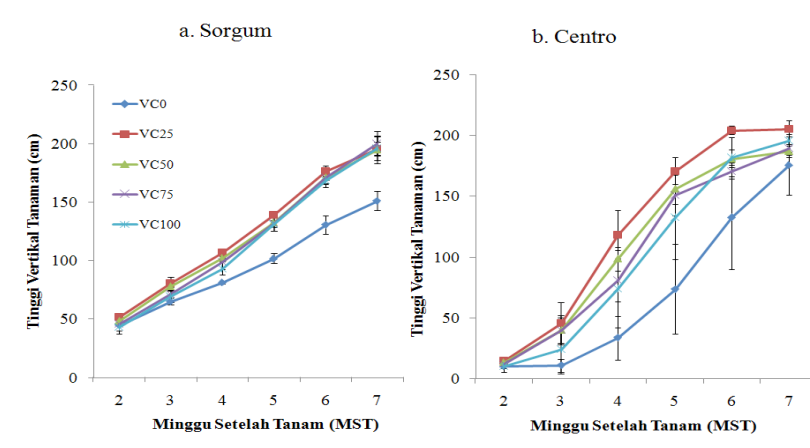

Gambar 1. Perubahan tinggi vertikal tanaman sorgum (a) dan sentro (b) pada berbagai level pemberian vermikompos
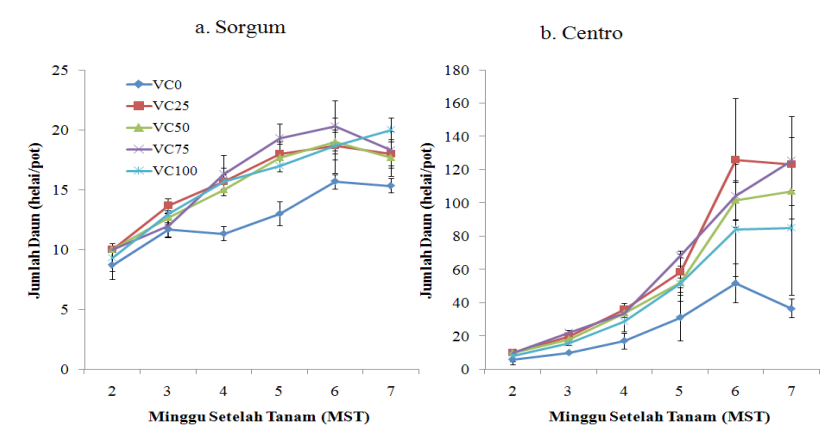

Gambar 2. Perubahan jumlah daun tanaman sorgum (a) dan sentro (b) pada berbagai level pemberian vermikompos

Jumlah daun tanaman sorgum dan centro sama seperti halnya dengan tinggi tanaman dipengaruhi oleh pemberian vermikompos, akan tetapi pemberian vermikompos $25 \%$ hingga $100 \%$ tidak terlalu memperlihatkan perbedaan baik pada tanaman sorgum maupun pada tanaman centro (Gambar 2). Walaupun demikian pemberian vermikompos sebanyak $25 \%$ pada tanaman centro pada akhir pertumbuhan mempunyai jumlah daun yang relatif lebih tinggi dibandingkan dengan pemberian yang lain. Penelitian Siswanto et al. (2004) juga menunjukan hal yang sama yaitu penambahan vermikompos dapat meningkatkan jumlah daun pada tanaman tempuyung. Peneliti ini juga menjelaskan bahwa peningkatan ini dihubungkan dengan adanya kandungan sitokin yang berperanan dalam pembentukan tunas baru.

\section{Berat Kering Bagian Atas (shoot) dan Akar (root) Tanaman}

Berat kering bagian atas tanaman pada fase vegetatif merupakan akumulasi dari berat batang dan daun. Pemberian vermikompos meningkatkan produktivitas tanaman yang digambarkan dengan terjadinya peningkatan berat kering bagian atas tanaman, baik pada tanaman sorgum maupun tanaman centro. Pengaruh tertinggi adalah dengan pemberian vermikompos sebanyak 25\% (VC25) dan semakin menurun dengan meningkatnya jumlah pemberian (Gambar 2).

Peningkatan produktivitas karena pemberian vermikompos juga tercatat pada tanaman kacang tanah, yaitu pemberian sebanyak $200 \mathrm{~g}$ memberikan hasil berat tanaman yang tertinggi hingga 100 hari setelah tanam, sedangkan pada media yang tidak diberikan vermikompos mempunyai berat tanaman terendah (Mathivanan et al., 2012)

Pola yang sama juga diperoleh pada pengaruh pemberian vermikompos terhadap akar tanaman (Gambar 3). Penurunan produktivitas ini dimungkinkan karena pada kondisi pemberian vermikompos yang semakin tinggi daya menahan air dari bahan ini semakin besar yang mengakibatkan kelembaban media tanam semakin tinggi. Kelembaban media yang tinggi akan mengganggu perkembangan akar yang selanjutnya akan menurunkan produksi tanaman. Hal ini terlihat dari perbadingan antara akar dan batang 
tanaman (root shoot ratio) yang mempunyai nilai yang rendah pada pemberian vermikompos 100\% (VC10o).
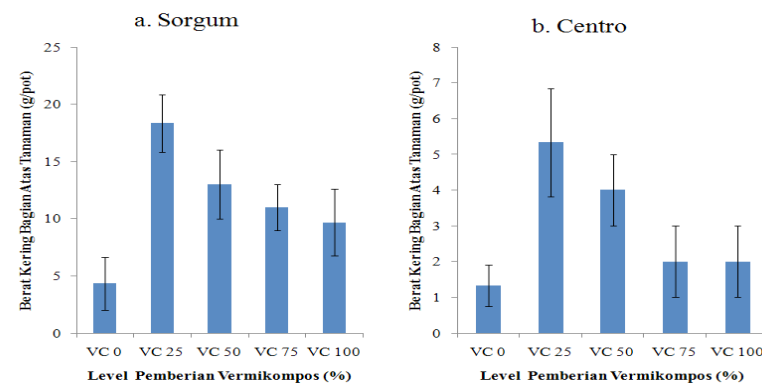

Gambar 3. Berat kering bagian atas tanaman sorgum (a) dan centro (b) pada berbagai level pemberian vermikompos

Tabel 2. Root Shoot Ratio Tanaman Sorgum dan Centro

\begin{tabular}{cccccc}
\hline \multicolumn{7}{c}{ Root Shoot Ratio } \\
\hline Sorgum & $0.34 \pm 0.17$ & $0.54 \pm 0.08$ & $0.36 \pm 0.06$ & $0.32 \pm 0.05$ & $0.27 \pm 0.09$ \\
Centro & $0.38 \pm 0.27$ & $0.40 \pm 0.06$ & $0.41 \pm 0.07$ & $0.16 \pm 0.06$ & $0.20 \pm 0.15$ \\
\hline
\end{tabular}

Kandungan dan Serapan N, P, K Bagian Atas Tanaman

Kandungan N, P, dan $\mathrm{K}$ pada tanaman tidak terlihat perbedaan dengan pemberian vermikompos (Tabel 3), kecuali untuk kandungan $\mathrm{P}$ dan $\mathrm{K}$ pada centro yang terlihat meningkat dengan pemberian vermikompos. Respon ini berbeda dengan pemberian pupuk anorganik yang umumnya meningkatkan kandungan mineral di dalam tanaman sehubungan dengan tingginya kandungan unsur hara di dalam pupuk anorganik tersebut. Sedangkan vermikompos mempunyai kandungan unsur hara yang relatif sedikit dibandingkan dengan kandungan hara pada pupuk anorganik (Tabel 2). Pengaruh vermikompos ini walaupun tidak terlalu terlihat pada kandungan unsur mineral di dalam tanaman, tetapi pada serapan N, P, dan $\mathrm{K}$ terlihat adanya peningkatan serapannya dengan penambahan vermikompos (Tabel 4). Walaupun kandungan $\mathrm{N}$ pada centro yang merupakan salah satu tanaman dari jenis leguminosa lebih tinggi dibandingkan dengan kandungan $\mathrm{N}$ pada tanaman sorgum, serapan $\mathrm{N}$ pada tanaman centro lebih rendah dibandingkan dengan serapan $\mathrm{N}$ pada sorgum hal ini karena produksi biomasanya yang lebih rendah. Serapan mineral merupakan perkalian antara suatu mineral dengan produksi bahan kering tanaman.
Tabel 3. Kandungan N, P, dan K Bagian Atas Tanaman (Shoot) Sorgum dan Centro

\begin{tabular}{lccccc}
\hline \multicolumn{5}{c}{ Kandungan N (\%) } \\
\hline Sorgum & VCO & VC25 & VC50 & VC75 & VC100 \\
Centro & $3.09 \pm 0.22$ & $2.60 \pm 0.43$ & $2.89 \pm 0.20$ & $2.73 \pm 0.21$ & $3.23 \pm 0.15$ \\
& $4.22 \pm 0.35$ & $3.96 \pm 0.19$ & $4.27 \pm 0.31$ & $4.15 \pm 0.23$ & $4.80 \pm 0.17$ \\
& \multicolumn{5}{c}{ Kandungan P (\%) } \\
Sorgum & VCO & VC25 & VC50 & VC75 & VC100 \\
Centro & $0.24 \pm 0.02$ & $0.25 \pm 0.01$ & $0.26 \pm 0.01$ & $0.24 \pm 0.01$ & $0.25 \pm 0.03$ \\
& $0.18 \pm 0.04$ & $0.24 \pm 0.01$ & $0.26 \pm 0.02$ & $0.36 \pm 0.02$ & $0.35 \pm 0.00$ \\
& \multicolumn{5}{c}{ Kandungan K (\%) } \\
Sorgum & $2.84 \pm 0.02$ & $3.07 \pm 0.57$ & $2.82 \pm 0.32$ & $3.20 \pm 0.60$ & $2.56 \pm 0.75$ \\
Centro & $1.91 \pm 0.13$ & $1.95 \pm 0.09$ & $2.30 \pm 0.19$ & $2.70 \pm 0.13$ & $3.01 \pm 0.24$ \\
\hline
\end{tabular}

Tabel 4. Serapan N, P, dan K Bagian Atas Tanaman (Shoot) Sorgum dan Centro

\begin{tabular}{lccccc}
\hline \multicolumn{5}{c}{ Serapan N (g/pot) } \\
\hline Sorgum & VCO & VC25 & VC50 & VC75 & VC100 \\
Centro & $0.39 \pm 0.05$ & $0.87 \pm 0.07$ & $1.03 \pm 0.11$ & $0.91 \pm 0.05$ & $1.15 \pm 0.09$ \\
& $0.18 \pm 0.11$ & $0.53 \pm 0.11$ & $0.41 \pm 0.06$ & $0.50 \pm 0.11$ & $0.53 \pm 0.22$ \\
& \multicolumn{5}{c}{ Serapan P $(g /$ pot) } \\
Sorgum & VCO & VC25 & VC50 & VC75 & VC100 \\
Centro & $0.03 \pm 0.00$ & $0.08 \pm 0.01$ & $0.09 \pm 0.01$ & $0.08 \pm 0.01$ & $0.09 \pm 0.01$ \\
& $0.01 \pm 0.00$ & $0.03 \pm 0.00$ & $0.03 \pm 0.00$ & $0.04 \pm 0.01$ & $0.04 \pm 0.01$ \\
& \multicolumn{5}{c}{ Serapan K (g/pot) } \\
Sorgum & $0.36 \pm 0.05$ & $1.03 \pm 0.17$ & $1.01 \pm 0.20$ & $1.08 \pm 0.23$ & $0.92 \pm 0.30$ \\
Centro & $0.08 \pm 0.04$ & $0.26 \pm 0.05$ & $0.22 \pm 0.01$ & $0.32 \pm 0.04$ & $0.33 \pm 0.13$ \\
\hline
\end{tabular}

\section{SIMPULAN}

Produktivitas tanaman sorgum dan centro meningkat dengan pemberian vermikompos dan peningkatan terbaik adalah pada pemberian vermikompos sebanyak 25\%. Kualitas nutrisi tidak dipengaruhi oleh pemberian vermikompos, sedangkan serapan mineral meningkat dengan pemberian vermikompos.

\section{DAFTAR PUSTAKA}

Mathivanan S, Chidabaram A, Sundaramoorthy P, Bakiyaraj R. 2012. Effect of vermicompost on growth and yield of groundnut (Arachis hypogaea L.).Inter J Envir Biol 2(1):7-11

Siswanto U, Sukarjo EI, Risnaily. 2004. Respon tanaman tempuyung (Sonchus arvensis L.) pada berbagai takaran dan aplikasi vermikompos. JIPI 6(2):83-90.

Wani KA, Manta RJ, Rao. 2012. Bioconversion of garden waste, kitchen waste and cow dung into value-added product using earthworm Eisenia foetida. Saudi JBiol Sci1(1):3-5. 